\title{
Meta-analysis of Randomized, Double-Blind, Placebo-Controlled Trials of Melatonin in Alzheimer's Disease
}

Running Title: Melatonin for Alzheimer's disease

\author{
1\#Yuan-Yuan Wang, PhD; \\ ${ }^{2 \# *}$ Wei Zheng, MD; \\ ${ }^{3}$ Chee H. Ng, MD; \\ ${ }^{4,5}$ Gabor S. Ungvari, MD, PhD; \\ ${ }^{1}$ Wei Wei, PhD \\ ${ }^{1 *}$ Yu-Tao Xiang, MD, PhD
}

1. Unit of Psychiatry, Faculty of Health Sciences, University of Macau, Macao SAR, China

2. The Affiliated Brain Hospital of Guangzhou Medical University (Guangzhou Huiai Hospital), Guangzhou, China

3. Department of Psychiatry, University of Melbourne, Melbourne, Victoria, Australia;

4. School of Psychiatry \& Clinical Neurosciences, University of Western Australia, Perth, Australia;

5. The University of Notre Dame Australia / Marian Centre, Perth, Australia

${ }^{\#}$ These authors equally contributed to this work.

${ }^{*}$ Address correspondence to Dr. Yu-Tao Xiang, 3/F, Building E12, Faculty of Health Sciences, University of Macau, Avenida da Universidade, Taipa, Macau SAR, China. Fax: +853-2288-2314; Phone: +853-8822-4223; E-mail: xyutly@gmail.com; or Dr. Wei Zheng, Guangzhou Huiai Hospital, Guangzhou, China; E-mail: zhengwei0702@163.com

This is the author manuscript accepted for publication and has undergone full peer review but has not been through the copyediting, typesetting, pagination and proofreading process, which may lead to differences between this version and the Version of Record. Please cite this article as doi: $10.1002 /$ gps.4571

This article is protected by copyright. All rights reserved. 


\section{Abstract}

Objective: This is a meta-analysis of randomized controlled trials (RCTs) of the efficacy of melatonin in Alzheimer's disease (AD).

Methods: Both English (PubMed, PsyclNFO, Embase, Cochrane Library databases and the Cochrane Controlled Trials Register) and Chinese (WanFang Database, Chinese Biomedical Database and China Journal Net) databases were systematically and independently searched by two authors from their inception until March 1, 2016. Weighted and standard mean differences (WMDs/SMDs), risk ratio (RR) $\pm 95 \%$ confidence intervals $(\mathrm{Cls})$ were calculated. In all cases, the random effects model were used.

Results: Seven studies $(n=462)$ with the duration ranging from 10 days to 24 weeks were identified and analyzed. AD patients receiving melatonin treatment showed prolonged total sleep time at night $(n=305 ;$ SMD: $0.26,95 \% \mathrm{Cl}: 0.01$ to $\left.0.51,1^{2}=9 \%, p=0.04\right)$. Melatonin did not improve cognitive abilities assessed by the Mini-Mental State Examination (MMSE) and the Alzheimer's disease Assessment cognitive subscale (ADAS-cog). The discontinuation rate was similar between the melatonin and placebo groups $(n=453, R R=0.77$, $95 \% \mathrm{Cl}: 0.51$ to $\left.1.16, \mathrm{l}^{2}=0 \%, \mathrm{p}=0.21\right)$.

Conclusion: Melatonin appears to be effective and safe in improving sleep quality in patients with $A D$.

Trial registration: PROSPERO: CRD42016039468

Key words: Melatonin, Alzheimer's disease, placebo, meta-analysis 


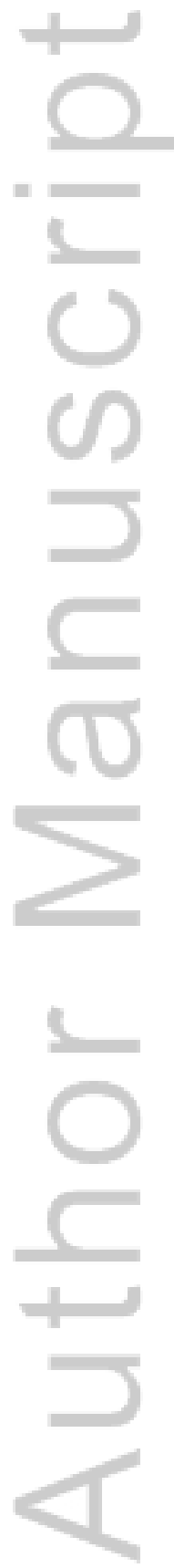

This article is protected by copyright. All rights reserved. 


\section{Key points:}

- Alzheimer's disease (AD), a neurodegenerative disorder, is one of the major causes of dementia worldwide.

- $A D$ is associated with a lack of plasma melatonin which is due to dysfunction in noradrenergic regulation and depletion of serotonin by an increase in monoamine oxidase

- This meta-analysis showed that melatonin appears to be effective and safe in improving sleep parameters in patients with $A D$. 


\section{Introduction}

Alzheimer's disease (AD), a neurodegenerative disorder, is the major cause of dementia worldwide (Jack, et al. 2013). Among other neurobiological changes, $A D$ is associated with a lack of plasma melatonin which is due to dysfunction in noradrenergic regulation and depletion of serotonin by an increase in monoamine oxidase (Perez, et al. 2016). Melatonin, a pineal hormone, is involved in the synchronization of the circadian rhythms of physiological functions (Mishima, et al. 1999) and is associated with the ability to induce sleep and regulate the circadian rhythm (Skene and Swaab 2003). Previous studies have found melatonin to be effective in treating $A D$, but their results were not consistent (Asayama, et al. 2003; Dowling, et al. 2008). A metaanalysis was conducted in 2013 on melatonin for sleep disorders and cognition in dementia (Xu, et al. 2015), but it included studies involving light therapy (Dowling et al. 2008; Riemersma-van der Lek, et al. 2008), rather than melatonin alone only.

To the best of our knowledge, no meta-analysis on melatonin alone for $A D$ has yet been published in English and Chinese databases. This meta-analysis assessed the efficacy of melatonin by extracting data from selected random controlled trials (RCTs) published in both English and Chinese language journals, the latter being not widely known internationally. 


\section{Methods}

\section{Selection Criteria}

According to the PICOS acronym, the following selection criteria were used: Participants $(P)$ : patients with $A D$ according to the included study diagnoses. Intervention (I): melatonin monotherapy excluding any other interventions (e.g., light therapy). Comparison (C): placebo. Outcomes (O): efficacy. Study design (S): randomized placebo-controlled, double blind trials. Case series, non-randomized studies, animal trials, reviews and meta-analyses were ineligible.

\section{Outcome parameters}

The primary outcome measure was sleep quality as assessed using sleep efficacy (SE). Key secondary outcomes included Total sleep time (TST) at night and TST at daytime; cognitive function as assessed using the Mini-Mental State Examination (MMSE) (Folstein, et al. 1975) and the Alzheimer's Disease Assessment cognitive subscale (ADAS-cog) (Rosen, et al. 1984); all-cause discontinuation and adverse drug reactions (ADRs). Intention-to-treat (ITT) datasets regarding clinical outcomes were extracted if provided.

\section{Search methods}

Major English (PubMed, PsyclNFO, Embase, Cochrane Library databases, the Cochrane Controlled Trials Register) and Chinese databases (WanFang 
Database, Chinese Biomedical Database and China Journal Net) were searched from their inception until March1, 2016. The search terms are listed in the Supplemental Methods. Furthermore, reference lists of eligible studies and relevant review articles (Xu et al. 2015) were hand-searched. First or corresponding author was contacted for obtaining more information if necessary.

\section{Data extraction}

Two reviewers (YYW and WZ) systematically and independently undertook the search, assessed eligibility and extracted data. Any inconsistencies during these procedures were checked and resolved by a third reviewer (YTX). Randomized cross-over study (Serfaty, et al. 2002) was only included when data for the first randomized study phase prior to cross-over were obtainable.

\section{Assessment of study quality}

The Cochrane Risk of Bias Tool was used to assess the risk of bias of included RCTs (Higgins and Green 2008). The recommendation for outcome measure of adjunctive melatonin for $A D$ using the grading of recommendations assessment, development, and evaluation (GRADE) system (Table S1) was rated as very low, low, moderate, or high (Atkins, et al. 2004; Balshem, et al. 2011). Moreover, we used the Jadad scale (Table 1) rating from 0 to 5 to assess the quality of included studies (J adad, et al. 1996). 


\section{Data synthesis and statistical analyses}

According to the recommendations of the Cochrane Collaboration Review, Review Manager Version 5.3 (http://www.cochrane.org) and STATA version 12.0 (http://www.stata.com/) were used to perform meta-analyses. The random effects model was performed in all cases (DerSimonian and Laird 1986)." For continuous data, standardized mean difference (SMD) with 95\% confidence intervals $(\mathrm{Cls})$ was used when outcome measurements were measured with different scales. Otherwise, weighted mean difference (WMD) with $95 \% \mathrm{Cls}$ was applied. For dichotomous data, risk ratio (RR) $\pm 95 \% \mathrm{Cl}$ was calculated. Furthermore, the number-needed-to-treat (NNT) or numberneeded-to-harm ( $\mathrm{NNH}$ ) by dividing 1 by the risk difference (RD) was used when pooled RR was significant. Study heterogeneity was measured using $\mathrm{I}^{2}$, with $I^{2}$ values greater than $50 \%$ indicating heterogeneity (Higgins, et al. 2003). In one study (Singer, et al. 2003) with three arms, the two fixed dose melatonin treatment arms were analyzed separately in order to assess the effect of dose, but were assigned half of the total patients randomly to placebo and to each melatonin arm in order to not inflate the number of placebotreated patients. In addition, we extracted the 24-week data from one study that lasted for 3.5 years, in order to reduce the heterogeneity (Riemersma-van der Lek et al. 2008). Publication bias was assessed using funnel plots and Egger's test (Egger, et al. 1997). All analyses were 2 tailed, with alpha set at 
0.05 .

\section{Results}

\section{Literature search}

A total of 517 potentially relevant articles in the initial database search were identified. Finally, 7 RCTs met the selection criteria and were included for the meta-analysis (Figure 1).

\section{Studies, participants and treatment characteristics}

As shown in Table 1, 462 patients were enrolled in the 7 studies which were conducted in the following countries: Japan, United Kingdom, United States, China, and the Netherlands. The sleep time in all included RCTs were assessed by actigraphy. The study duration ranged from 10 days to 24 weeks. Of the 7 RCTs, 2 (Riemersma-van der Lek et al. 2008; Serfaty et al. 2002) included patients with $A D(74 \%)$ and other types of dementia $(26 \%)$, and the rest included patients with AD only (Asayama et al. 2003; Gao, et al. 2009a; Gehrman, et al. 2009; Singer et al. 2003; Wade, et al. 2014). One study did not mention the diagnostic criteria of AD (Wade et al. 2014), and the rest used Diagnostic Statistical Manual of Mental Disorders, Fourth Edition (DSM-IV) and/or Clinical Diagnosis of the National Institute of Neurological and Communicative Disorders and Stroke and the Alzheimer's disease and Related Disorders Association (NINCDS-ADRDA) (Asayama et al. 2003; Gao et al. 
2009a; Gehrman et al. 2009; Riemersma-van der Lek et al. 2008; Serfaty et al. 2002; Singer et al. 2003).

One study (Riemersma-van der Lek et al. 2008) had four treatment arms. We only selected and extracted the data of melatonin compared with placebo. In the study conducted by Singer and colleagues we included data of two doses (2.5 $\mathrm{mg}$ and $10 \mathrm{mg}$ ) of melatonin with placebo (Singer et al. 2003).

\section{Risk of bias}

The risk of bias of the included studies were summarized in supplemental Figure 1. While all RCTs were doubled-blind studies, 4 RCTs mentioned randomization methods with a specific description, 2 RCTs were rated as low risk regarding allocation concealment, and 1 RCT used a protocol registration. Furthermore, 6 RCTs with 7 treatment arms reported loss to follow-up and 1 of them used ITT analysis for incomplete outcome data. The quality of evidence was ranged from "moderate" $(67 \%)$ to "high" (33\%) according to the GRADE approach (Table 2). Jadad score ranged from 3 to 5 (Table 1 ).

\section{Primary outcomes}

Of the 7 included RCTs, 4 RCTs (Gehrman et al. 2009; Riemersma-van der Lek et al. 2008; Serfaty et al. 2002; Singer et al. 2003) with 5 treatment arms reported sleep efficacy as assessed by actigraphy. Melatonin was not associated with significant superiority in improvement of sleep efficacy $(n=287$, 
SMD: $0.14,95 \% \mathrm{Cl}:-0.17$ to $0.44, \mathrm{I}^{2}=33 \%, \mathrm{p}=0.38$, Figure 2$)$ when compared with placebo. Due to the limited number of included studies for primary outcome, publication bias could not be tested using funnel plots and Egger's test (Sterne, et al. 2011).

\section{Secondary outcome}

Total sleep time: 6 RCTs (Asayama et al. 2003; Gehrman et al. 2009; Riemersma-van der Lek et al. 2008; Serfaty et al. 2002; Singer et al. 2003; Wade et al. 2014) with 7 treatment arms and 3 RCTs (Asayama et al. 2003; Gehrman et al. 2009; Singer et al. 2003) with 4 treatment arms provided data of TST at night and daytime, respectively. However, the study conducted by Wade and colleagues only provided baseline and the change of scores, which was not able to be calculated into post intervention score and to be further analyzed. Compared with placebo, subjects on melatonin experienced a significant prolongation in TST at night $(n=305 ;$ SMD: $0.26,95 \% \mathrm{Cl}: 0.01$ to $0.51,1^{2}=9 \%, p=0.04$, Figure 2$)$. However, there was no significant difference in TST in the daytime $\left(n=210\right.$; SMD: $0.15,95 \% \mathrm{Cl}:-0.14$ to $0.44,1^{2}=0 \%$, $p=0.31$, Figure 2) between the two groups.

Cognitive function: 5 RCTs (Asayama et al. 2003; Gao et al. 2009a; Riemersma-van der Lek et al. 2008; Singer et al. 2003; Wade et al. 2014) with 6 treatment arms and 3 RCTs (Asayama et al. 2003; Singer et al. 2003; Wade 
et al. 2014) with 4 treatment arms assessed cognitive function by the MMSE and ADAS-cog, respectively. However, the study conducted by Singer and colleagues only provided baseline and the change of scores, which was not able to be calculated into post intervention score and to be further analyzed. There was no significant difference in the MMSE $(n=182 ;$ SMD $=0.33,95 \%$ $\mathrm{Cl}:-0.06$ to $0.73, \mathrm{I}^{2}=38 \%, \mathrm{p}=0.09$, Figure 3 ) and ADAS-cog total scores between the two groups $\left(n=75 ; S M D=-0.25,95 \% \mathrm{Cl}:-0.70\right.$ to $0.21,1^{2}=0 \%$, $p=0.29$, Figure 3).

\section{All cause discontinuation}

Forest plot for discontinuation are presented in Figure 4. The pooled Risk Ratios (RR) with $95 \% \mathrm{Cl}$ were calculated using random-effects models. The discontinuation rate was similar between the melatonin and placebo groups $\left(n=453, R R=0.77,95 \% \mathrm{Cl}: 0.51\right.$ to $1.16, \mathrm{l}^{2}=0 \%, p=0.21$, Figure 4$)$.

\section{Discussion}

This was the first meta-analysis assessing the efficacy of melatonin alone for $A D$, and also the first study examining the respective effects of melatonin on TST at night and daytime. The results showed that melatonin significantly improved total sleep time at night in $A D$ patients, but improvement in cognition was not apparent.

Sleep disturbance, including reduced nocturnal sleep time, is common in 
patients with $A D$ and is also closely associated with the decline of patients' cognitive and social functions (Yin, et al. 2015). The beneficial effect of melatonin on sleep has positive implications for AD. Shorter sleep duration and poor sleep quality have been associated with increased risk of $A D(J u$, et al. 2014; Lim, et al. 2013; Spira, et al. 2013), and hence, if modifiable, could perhaps attenuate the $A D$ progression. However, the results of this metaanalysis did not show significant improvement in cognitive function. The impact of sleep disturbances on the development of $A D$, if any, may take many years. The study duration in these studies were between 10 days and 24 weeks, thus improvement in cognitive functions were not observed. In addition, we examined TST at night and daytime separately, and found that melatonin only significantly improved nocturnal TST, but not in the daytime. This perhaps is related to the secretion and effect of melatonin that is stimulated during darkness and suppressed by light at daytime.

\section{Comparison with other meta-analyses}

One previous meta-analysis (Xu et al. 2015) examined the effects of melatonin and light therapy on sleep quality and cognitive function in dementia patients and found the advantage of melatonin and light therapy in improving sleep quality, which is consistent with our results. Apart from focusing on melatonin alone, the Jadad scale and more recent published RCTs (Wade et al. 2014) were included in our study. 


\section{Limitations}

There are several limitations in this meta-analysis. First, the dose of melatonin varied in different studies, ranging from $2 \mathrm{mg}$ to $10 \mathrm{mg}$, which did not allow any assessment of the dose-response relationship. Second, one study with the duration of 3.5 years (Riemersma-van der Lek et al. 2008) was included. In order to make consistent comparison with other studies and decrease the heterogeneity, only the data during the 24 weeks were included for analyses. Third, some variables that could influence sleep, such as noise, pain, discomfort, emotional distress, medical and psychiatric comorbidities and medications, were not provided in these studies. Fourth, no mention was made about daytime naps in either of the studies and whether naps were included in the TST. Finally, the adverse effect of melatonin were not analyzed due to limited information.

\section{Conclusions}

The results of this meta-analysis support the efficacy of melatonin monotherapy in sleep parameters in patients with AD. However, well-designed longer term RCTs are still needed to confirm the usefulness of melatonin in clinical practice. The impact of sleeping pills on the efficacy of melatonin should be examined. Future studies should use more complex neurocognitive tests, such as Delayed Word Recall and the Stroop tests. 


\section{Disclosure of interest}

The authors declare that they have no conflicts of interest concerning this article.

\section{Acknowledgements}

N/A.

This article is protected by copyright. All rights reserved. 


\section{Reference}

Asayama K, Yamadera H, I to T, Suzuki H, Kudo Y \& Endo S 2003 Double blind study of melatonin effects on the sleep-wake rhythm, cognitive and noncognitive functions in Alzheimer type dementia. Journal of nippon medical school 70 334-341.

Atkins D, Best D, Briss PA, Eccles M, Falck-Ytter Y, Flottorp S, Guyatt GH, Harbour RT, Haugh MC, Henry D, et al. 2004 Grading quality of evidence and strength of recommendations. BMJ 3281490.

Balshem $H$, Helfand M, Schunemann HJ, Oxman AD, Kunz R, Brozek J, Vist GE, Falck-Ytter Y, Meerpohl J, Norris S, et al. 2011 GRADE guidelines: 3. Rating the quality of evidence. J. Clin. Epidemiol. 64 401-406.

DerSimonian R \& Laird N 1986 Meta-analysis in clinical trials. Control. Clin. Trials 7 177-188.

Dowling GA, Burr RL, Van Someren EJ, Hubbard EM, Luxenberg JS, Mastick J \& Cooper BA 2008 Melatonin and bright-light treatment for rest-activity disruption in institutionalized patients with Alzheimer's disease. J Am Geriatr Soc 56 239-246.

Egger M, Davey Smith G, Schneider M \& Minder C 1997 Bias in meta-analysis detected by a simple, graphical test. BMJ 315 629-634.

Folstein MF, Folstein SE \& McHugh PR 1975 "Mini-mental state". A practical method for grading the cognitive state of patients for the clinician. J. Psychiatr. Res. 12 189-198. 
Gao QW, Liu Y, Luo GQ, Xiang W \& Peng KR 2009a Effect of melatonin on mild Alzheimer's disease in elderly male patients. . Parct Geriatr 23 56-58.

Gao QW, Liu Y, Luo GQ, Xiang W \& Peng KR 2009b Effect of melatonin on mild Alzheimer's disease in elderly male patients. Parct Geriatr 23 56-58.

Gehrman PR, Connor DJ, Martin JL, Shochat T, Corey-Bloom J \& Ancoli-Israel S 2009 Melatonin fails to improve sleep or agitation in double-blind randomized placebo-controlled trial of institutionalized patients with Alzheimer disease. The American journal of geriatric psychiatry 17 166-169.

Higgins JP \& Green S 2008 Cochrane handbook for systematic reviews of interventions: Wiley Online Library.

Higgins JP, Thompson SG, Deeks JJ \& Altman DG 2003 Measuring inconsistency in meta-analyses. BMJ 327 557-560.

Jack CR, Knopman DS, Jagust WJ, Petersen RC, Weiner MW, Aisen PS, Shaw LM, Vemuri P, Wiste HJ \& Weigand SD 2013 Tracking pathophysiological processes in Alzheimer's disease: an updated hypothetical model of dynamic biomarkers. The Lancet Neurology 12 207-216.

Jadad AR, Moore RA, Carroll D, Jenkinson C, Reynolds DJ, Gavaghan DJ \& McQuay HJ 1996 Assessing the quality of reports of randomized clinical trials: is blinding necessary? Control. Clin. Trials 17 1-12.

J u YE, Lucey BP \& Holtzman DM 2014 Sleep and Alzheimer disease pathology-a bidirectional relationship. Nature reviews. Neurology 10 115-119.

Lim AS, Yu L, Kowgier M, Schneider JA, Buchman AS \& Bennett DA 2013 
Modification of the relationship of the apolipoprotein E epsilon4 allele to the risk of Alzheimer disease and neurofibrillary tangle density by sleep. JAMA neurology 70 1544-1551.

Mishima K, Tozawa T, Satoh K, Matsumoto Y, Hishikawa Y \& Okawa M 1999 Melatonin secretion rhythm disorders in patients with senile dementia of Alzheimer's type with disturbed sleep-waking. Biological psychiatry 45 417421.

Perez A, Li T, Hernandez S, Zhang R \& Cao C 2016 The rationale of using coffee and melatonin as an alternative treatment for Alzheimer's Disease. J Alzheimers Dis Parkinsonism 6 2161-0460.1000205.

Riemersma-van der Lek RF, Swaab DF, Twisk J, Hol EM, Hoogendijk WJ \& Van Someren EJ 2008 Effect of bright light and melatonin on cognitive and noncognitive function in elderly residents of group care facilities: a randomized controlled trial. Jama 299 2642-2655.

Rosen WG, Mohs RC \& Davis KL 1984 A new rating scale for Alzheimer's disease. The American journal of psychiatry 141 1356-1364.

Serfaty M, Kennell - Webb S, Warner J, Blizard R \& Raven P 2002 Double blind randomised placebo controlled trial of low dose melatonin for sleep disorders in dementia. International journal of geriatric psychiatry 17 1120-1127.

Singer C, Tractenberg RE, Kaye J, Schafer K, Gamst A, Grundman M, Thomas R \& Thal LJ 2003 A multicenter, placebo-controlled trial of melatonin for sleep disturbance in Alzheimer's disease. Sleep 26893. 
Skene DJ \& Swaab DF 2003 Melatonin rhythmicity: effect of age and Alzheimer's disease. Experimental gerontology 38 199-206.

Spira AP, Gamaldo AA, An Y, Wu MN, Simonsick EM, Bilgel M, Zhou Y, Wong DF, Ferrucci L \& Resnick SM 2013 Self-reported sleep and beta-amyloid deposition in community-dwelling older adults. JAMA neurology 70 1537-1543.

Sterne JA, Sutton AJ, Ioannidis JP, Terrin N, Jones DR, Lau J, Carpenter J, Rücker G, Harbord RM \& Schmid CH 2011 Recommendations for examining and interpreting funnel plot asymmetry in meta-analyses of randomised controlled trials. Bmj 343 d4002.

Wade AG, Farmer M, Harari G, Fund N, Laudon M, Nir T, Frydman-Marom A \& Zisapel N 2014 Add-on prolonged-release melatonin for cognitive function and sleep in mild to moderate Alzheimer's disease: a 6-month, randomized, placebo-controlled, multicenter trial. Clin Interv Aging 9 947-961.

Xu J, Wang LL, Dammer EB, Li CB, Xu G, Chen SD \& Wang G 2015 Melatonin for sleep disorders and cognition in dementia: a meta-analysis of randomized controlled trials. American journal of Alzheimer's disease and other dementias 30 439-447.

Yin Y, Liu Y, Zhuang J, Pan X, Li P, Yang Y, Li Y-P, Zhao Z-Q, Huang L-Q \& Zhao Z-X 2015 Low-Dose Atypical Antipsychotic Risperidone Improves the 5-Year Outcome in Alzheimer's Disease Patients with Sleep Disturbances. Pharmacology 96 155-162. 


\section{Supplemental Methods}

The search terms were presented as follows: (Disease, Alzheimer OR Alzheimer Sclerosis OR Sclerosis, Alzheimer OR Alzheimer Syndrome OR Syndrome, Alzheimer OR Alzheimer Dementia OR Dementia, Alzheimer OR Alzheimer-Type Dementia OR Alzheimer Type Dementia OR Dementia, Alzheimer-Type OR Primary Senile Degenerative Dementia OR Dementia, Senile OR Senile Dementia OR Dementia, Alzheimer Type OR Alzheimer Type Dementia OR Senile Dementia, Alzheimer Type OR Alzheimer Type Senile Dementia OR Dementia, Primary Senile Degenerative OR Alzheimer's Disease OR Disease, Alzheimer's OR Acute Confusional Senile Dementia OR Senile Dementia, Acute Confusional OR Dementia, Presenile OR Presenile Dementia OR Alzheimer Disease, Late Onset OR Late Onset Alzheimer Disease OR Alzheimer's Disease, Focal Onset OR Focal Onset Alzheimer's Disease OR Familial Alzheimer Disease OR Alzheimer Disease, Early Onset OR Early Onset Alzheimer Disease OR Presenile Alzheimer Dementia) AND (Mélatonine OR Melatonin).

This article is protected by copyright. All rights reserved. 


\section{Contributors}

Study design: Yuan-Yuan Wang, Wei Zheng. Data collection, analysis and interpretation: Yuan-Yuan Wang, Wei Zheng. Drafting of the manuscript: Yuan-Yuan Wang, Wei Zheng, Yu-Tao Xiang. Critical revision of the manuscript: Chee $\mathrm{H}$. Ng, Gabor S. Ungvari, Wei Wei. Approval of the final version for publication: all co-authors. 
Table 1. Characteristics of the RCTs

\begin{tabular}{|c|c|c|c|c|c|c|c|c|c|c|c|}
\hline Authors & Country & Studies & & & Participants & & Interv & tion & Out & omes & Jada \\
\hline$=$ & & & $\mathrm{N}$ & $\begin{array}{c}\text { Male } \\
(\%)\end{array}$ & Diagnostic criteria & Setting & $\begin{array}{l}\text { Dose } \\
\text { (mg/day) }\end{array}$ & $\begin{array}{l}\text { Duration } \\
\text { (Weeks) }\end{array}$ & Sleep & $\begin{array}{l}\text { Cognitive } \\
\text { function }\end{array}$ & $\begin{array}{c}d \\
\text { score }\end{array}$ \\
\hline Serfaty et al, 2002 & UK & $\begin{array}{c}\text { DB, } \\
\text { crossover }^{\mathrm{a}}\end{array}$ & 44 & 64 & DSM-IV & $\begin{array}{l}\text { Nursing } \\
\text { home; } \\
\text { home } \\
\text { setting; } \\
\text { hospital } \\
\text { setting }\end{array}$ & $\begin{array}{l}6 \mathrm{mg} \\
\text { exogenou } \\
\mathrm{s} \\
\text { melatonin }\end{array}$ & 2 & TST(N), SE, & $\begin{array}{l}\text { MMSE , } \\
\text { ADAS-cog }\end{array}$ & 5 \\
\hline Asayama et al, 2003 & Japan & DB & 20 & 15 & $\begin{array}{l}\text { NINCDS-ADRDA, } \\
\text { DSM-IV }\end{array}$ & Inpatient & $\begin{array}{c}3 \mathrm{mg} \\
\text { melatonin }\end{array}$ & 4 & $\begin{array}{l}\text { TST(N), } \\
\text { TST(D) }\end{array}$ & MMSE & 3 \\
\hline Singer et al, 2003 & USA & DB & 157 & 44 & NINCDS-ADRDA & $\begin{array}{l}\text { Alzheimer } \\
\text { Disease } \\
\text { research } \\
\text { center }\end{array}$ & $\begin{array}{l}2.5 \mathrm{mg} \\
\text { sustained- } \\
\text { release; } \\
10 \mathrm{mg} \\
\text { immediate } \\
\text {-release } \\
\text { melatonin }\end{array}$ & 8 & $\begin{array}{l}\text { TST(N), SE, } \\
\text { TST(D) }\end{array}$ & $\begin{array}{l}\text { MMSE, } \\
\text { ADAS-cog }\end{array}$ & 3 \\
\hline $\begin{array}{l}\text { Riemersma-van der } \\
\text { Lek et al, } 2008\end{array}$ & $\begin{array}{l}\text { Netherlan } \\
\text { ds }\end{array}$ & DB & 91 & 14 & $\begin{array}{l}\text { NINCDS-ADRDA, } \\
\text { DSM-IV }\end{array}$ & $\begin{array}{l}\text { Dutch } \\
\text { homes for } \\
\text { the elderly }\end{array}$ & $\begin{array}{l}2.5 \mathrm{mg} \\
\text { melatonin }\end{array}$ & $24^{b}$ & TST(N), SE & MMSE & 5 \\
\hline Gehrman et a,2009 & USA & DB & 41 & 32 & NINCDS-ADRDA & $\begin{array}{l}\text { Nursing } \\
\text { home }\end{array}$ & $\begin{array}{c}8.5 \mathrm{mg} \\
\text { immediate } \\
\text { release } \\
\text { and } 1.5 \\
\text { mg time } \\
\text { release }\end{array}$ & 10 days & $\begin{array}{l}\text { TST(N), } \\
\text { TST(D) }\end{array}$ & NR & 4 \\
\hline Gao et al, 2009 & China & DB & 36 & 100 & NINCDS-ADRDA & Outpatient & $\begin{array}{l}2.9 \mathrm{mg} \\
\text { melatonin }\end{array}$ & 24 & NR & MMSE, & 3 \\
\hline Wade et al, 2014 & UK, USA & DB & 73 & NR & NR & Outpatient & $\begin{array}{l}2 \mathrm{mg} \\
\text { prolonged- } \\
\text { release } \\
\text { melatonin } \\
\end{array}$ & 24 & $\mathrm{TST}(\mathrm{N})$ & $\begin{array}{l}\text { MMSE, } \\
\text { ADAS-cog }\end{array}$ & 4 \\
\hline
\end{tabular}

${ }^{a}$ We only extracted data from the first phrase; only the MMSE score for the whole group was provided, therefore it was not included for analyses.

${ }^{\mathrm{b}}$ The whole trial duration was 3.5 years; only data for 24 weeks were extracted to reduce the heterogeneity of the studies

Abbreviations: ADAS-cog, Alzheimer's Disease Assessment Scale-Cognitive subscale; DB, double blind, DSM-IV, Diagnostic Statistical Manual of Mental Disorders, Fourth Edition; RCTs, Randomized Controlled Trials; MMSE, Mini-Mental State Examination; NR, not report; NINCDS-ADRDA, Clinical Diagnosis of the National Institute of Neurological and Communicative Disorders and Stroke and the Alzheimer's disease and Related Disorders

This article is protected by copyright. All rights reserved. 
Association; SE, Sleep efficacy; TST, total sleep time; TST (D), total sleep time (day time); TST (N), total sleep time (night time)

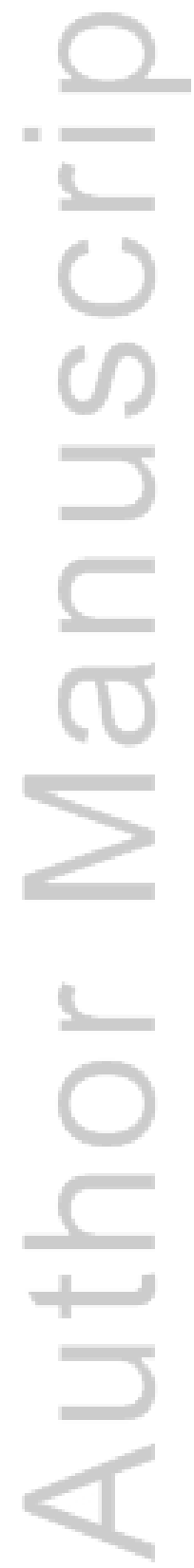

This article is protected by copyright. All rights reserved. 
Table 2. GRADE Analyses: Melatonin versus Placebo for Alzheimer's disease

\begin{tabular}{|c|c|c|c|c|c|c|c|c|}
\hline $\begin{array}{l}\text { Primary/secondary } \\
\text { outcome }\end{array}$ & N (arms) & $\begin{array}{l}\text { Risk of } \\
\text { bias }\end{array}$ & Inconsistency & Indirectness & Imprecision & $\begin{array}{l}\text { Publication } \\
\text { bias }\end{array}$ & $\begin{array}{l}\text { Large } \\
\text { effect }\end{array}$ & $\begin{array}{l}\text { Overall quality } \\
\text { of evidence }^{\mathrm{a}}\end{array}$ \\
\hline Sleep efficacy & $287(5)$ & No & No & No & No & Serious $^{b}$ & No & $\begin{array}{l}+/+/-/ ; \\
\text { Moderate }\end{array}$ \\
\hline Total sleep time (at day) & $210(4)$ & No & No & No & No & No & No & $+/+/+/+/ ;$ High \\
\hline Total sleep time (at night) & $305(6)$ & No & No & No & No & Serious $^{b}$ & No & $\begin{array}{l}+/+/+/-/ \\
\text { Moderate }\end{array}$ \\
\hline $\begin{array}{l}\text { MMSE endpoint/change } \\
\text { total score }\end{array}$ & $182(4)$ & No & No & No & No & Serious $^{b}$ & No & $\begin{array}{l}+/+/+/-/ \\
\text { Moderate }\end{array}$ \\
\hline $\begin{array}{l}\text { ADAS-cog } \\
\text { endpoint/change total } \\
\text { score }\end{array}$ & $75(2)$ & No & No & No & No & Serious $^{b}$ & No & $\begin{array}{l}+/+/+/-/ \\
\text { Moderate }\end{array}$ \\
\hline All cause discontinuation & $453(6)$ & No & No & No & No & No & No & $+/+/+/+/ ;$ High \\
\hline \multicolumn{9}{|c|}{$\begin{array}{l}\text { GRADE = grading of recommendations assessment, development, and evaluation; MMSE=Mini-Mental State Examination; ADAS-cog=Alzheimer's } \\
\text { Disease Assessment cognitive subscale. } \\
\text { a GRADE Working Group grades of evidence: High quality = further research is very unlikely to change our confidence in the estimate of effect. } \\
\text { Moderate quality = further research is likely to have an important impact on our confidence in the estimate of effect and may change the estimate. Low } \\
\text { quality = further research is very likely to have an important impact on our confidence in the estimate of effect and is likely to change the estimate. Very } \\
\text { low quality = we are very uncertain about the estimate. } \\
{ }^{b} \text { For continuous outcomes, } \mathrm{N}<400 \text {. } \\
{ }^{\mathrm{c}} \text { All studies reported as having a serious inconsistency had } \mathrm{I}^{2}>50 \% \text {. }\end{array}$} \\
\hline
\end{tabular}

This article is protected by copyright. All rights reserved. 


\section{University Library}

\section{- M M N E R VA A gateway to Melbourne's research publications}

Minerva Access is the Institutional Repository of The University of Melbourne

Author/s:

Wang, Y-Y;Zheng, W;Ng, CH;Ungvari, GS;Wei, W;Xiang, Y-T

Title:

Meta-analysis of randomized, double-blind, placebo-controlled trials of melatonin in Alzheimer's disease

Date:

2017-01-01

Citation:

Wang, Y. -Y., Zheng, W., Ng, C. H., Ungvari, G. S., Wei, W. \& Xiang, Y. -T. (2017). Metaanalysis of randomized, double-blind, placebo-controlled trials of melatonin in Alzheimer's disease. INTERNATIONAL JOURNAL OF GERIATRIC PSYCHIATRY, 32 (1), pp.50-57. https:// doi.org/10.1002/gps.4571.

Persistent Link:

http://hdl.handle.net/11343/291740 